\title{
BERGSONISMO, PSICOLOGIA E LIBERDADE ${ }^{1}$
}

\begin{abstract}
RESUMO. Examina-se neste ensaio o conceito bergsoniano de liberdade. Essa análise passa pelo exame do conceito de grandeza intensiva e pela discussão das teses deterministas e indeterministas. Mas é na descrição do sentimento da graça que se pode encontrar o paradigma da experiência da liberdade. Sugere-se que o tratamento bergsoniano da liberdade lança um desafio de caráter epistemológico à psicologia científica: apresentar-se como psicologia estética, isto é, uma psicologia que resgataria o saber sensível e assumiria uma posição crítica com respeito ao pensamento intelectual. Diante dessa provocação, resta indagar: a psicologia estaria pronta para pensar a ciência como uma arte?
\end{abstract}

Palavras-chave: bergsonismo, determinismo, liberdade.

\section{BERGSONISM, PSYCHOLOGY AND FREEDOM}

\begin{abstract}
Current essay deals with the Bergsonian concept of freedom. Analysis undertakes an examination of the concept of intensive magnitude and discusses the determinists and indeterminists' theses. The paradigm of the freedom experience may be found in a description of the feeling of beauty. The Bergsonian treatment of freedom sets an epistemological challenge to scientific Psychology: it presents itself as esthetic Psychology, or rather, a type of psychology that recuperates the knowledge of the senses and it takes a critical stance on intellectual knowledge. A provocative question may be asked: Is Psychology prepared to consider science as Art?
\end{abstract}

Key words: Bergsonism, determinism, freedom.

\section{BERGSONISMO, PSICOLOGÍA Y LIBERTAD}

RESUMEN. En este ensayo se examina el concepto bergsoniano de libertad. Ese análisis pasa por el examen del concepto de grandeza intensiva y por la discusión de las tesis deterministas e indeterministas. Sin embargo es en la descripción del sentimiento de la gracia que se puede encontrar el paradigma de la experiencia de la libertad. Se sugiere que el tratamiento bergsoniano de la libertad lanza un desafío de carácter epistemológico a la psicología científica: presentarse como psicología estética, es decir, una psicología que rescataría el saber sensible y asumiría una posición crítica con respecto al pensamiento intelectual. Ante esa provocación, resta indagar: ¿la psicología estaría lista para pensar la ciencia como un arte?

Palabras-clave: bergsonismo, determinismo, libertad.

Como a psicologia científica lida com a liberdade? Eis a questão que está no horizonte deste ensaio. $\mathrm{O}$ tratamento da liberdade impõe desafios à psicologia científica. De um lado, espera-se que a ciência psicológica ofereça respostas a questões notadamente humanas. A liberdade constitui um desses temas que reclamam um posicionamento da psicologia. Por outro lado, o conhecimento psicológico aspirante ao status de ciência deve moldar-se aos cânones do método científico: objetividade, medição, precisão, previsão, controle, experimentação. Ora, como explicar cientificamente a liberdade sem descaracterizá-la como um assunto das ciências humanas?

Para sondar esse aparente paradoxo recorreremos a um filósofo do século XIX, Henri Bergson (18591941), que traz contribuições interessantes à discussão da liberdade como um problema central à psicologia científica. Dessa forma, este ensaio pretende examinar o conceito bergsoniano de liberdade e, a partir dessa análise, discutir possíveis encaminhamentos para o tratamento da liberdade pela psicologia científica. Isso

\footnotetext{
1 Apoio: FAPESP.

* Mestre em Filosofia. Doutoranda do Programa de Pós-Graduação em Filosofia da Universidade Federal de São Carlos.
} 
será feito com base na primeira grande obra de Bergson, Ensaio Sobre os Dados Imediatos da Consciência (1927/1988). Nesse livro, poderemos encontrar os elementos necessários para conduzir o tema em questão. Inauguremos essa empreitada examinando algumas noções basilares da teoria bergsoniana, que nos ajudarão a entender a liberdade na perspectiva desse autor.

\section{CRÍTICA BERGSONIANA À PSICOLOGIA CIENTÍFICA: O CONCEITO DE GRANDEZA INTENSIVA}

Bergson (1927/1988) estabeleceu um intenso diálogo com a psicologia, justamente no período em que esta tentava se estabelecer como uma disciplina científica, no final do século XIX. Assim, a psicofísica, uma das propostas iniciais de psicologia científica, foi o alvo nuclear de Bergson. É célebre a discussão bergsoniana de conceitos primordiais da psicologia, como a noção de grandeza intensiva, com a qual a psicofísica aspirava revestir a nova disciplina dos atributos genuínos da ciência: objetividade, exatidão, medição e previsão. O conceito de grandeza intensiva, no vocabulário bergsoniano, é um misto mal-elaborado, pois agrega coisas que são distintas por natureza: extensão e inextensão. Examinemos essa tese bergsoniana. As relações de quantificação, que caracterizam a grandeza, baseiam-se nas relações de continente e conteúdo. O problema consiste em aplicar essa noção de grandeza aos estados de consciência, isto é, em combinar a noção de grandeza com a de intensidade, como se a última fosse um caso específico da primeira. Expressões dessa confusão podem ser vislumbradas nos seguintes questionamentos: uma sensação mais intensa contém uma sensação de menor intensidade? Ou ainda: a sensação de maior intensidade seria resultado de intensidades inferiores da mesma sensação, revelando, aqui, uma relação de continente e conteúdo? Para Bergson essas formulações baseiam-se em um engano, pois relacionam o que não tem relação:

\footnotetext{
"que pode haver de comum, do ponto de vista da grandeza, entre o extensivo e o intensivo, entre o extenso e o inextenso? Se, no primeiro caso, chamamos maior quantidade à que contém a outra, por que falar ainda de quantidade e de grandeza quando já não há continente nem conteúdo? Se uma quantidade pode crescer e diminuir, se nela deparamos, por assim dizer, com o menos dentro do mais, não será por isso mesmo divisível, por isso mesmo extensa? E
}

não há, então, contradição em falar de quantidade inextensiva?" (Bergson, 1927/1988, p. 12).

Ao afirmar que uma "sensação cresce", admitimos que a sensação, inextensa, pode ser expressa, sem que isso lhe altere a natureza, através das propriedades da grandeza, que é extensão ou pura quantidade. A psicologia ficaria à vontade, então, para dizer "uma dor mais intensa ou menos intensa", e arquitetar procedimentos complexos para mensurar tal mudança de intensidade; tratando diferenças de natureza (extensão e inextensão) como diferenças de grau.

A dissociação operada por Bergson (1927/1988) desse misto mal-elaborado mostra que o uso, por parte da psicologia, do conceito de grandeza intensiva acaba, ao fim e ao cabo, por frustrar o projeto dessa disciplina de instituir-se como ciência. Primeiramente, segundo o filósofo, a noção de grandeza intensiva não pode servir como um critério legítimo de demarcação entre conhecimento científico e conhecimento do senso comum. Bergson considera que a defesa dessa tese pelos psicólogos não passa de mera ilusão, pois o conhecimento científico é orientado pelo mesmo equívoco presente no pensamento ordinário: a confusão entre extenso e inextenso. A diferença entre ciência e senso comum reside, apenas, na parafernália de instrumentos e procedimentos experimentais que são empregados pelos cientistas. Com efeito, vê-se malograda a proposta da psicologia de eleger o conceito de grandeza intensiva como representativo do pensamento rigoroso, em oposição ao conhecimento impreciso e superficial do senso comum.

Em segundo lugar, a confusão entre o extenso e o inextenso existente no pensamento científico e cotidiano remete, segundo Bergson (1927/1988), a uma ilusão fundamental constitutiva da própria condição humana: a experiência consciente é regida pela estrutura da linguagem. Mais explicitamente, a confusão entre quantidade e qualidade não é apenas o resultado de uma infidelidade à experiência imediata, mas é fruto de uma tendência intelectual, inerente à consciência humana, de pensar as diferenças de natureza em termos de diferenças de grau. A questão é que a psicologia tem pretensões científicas, e pronuncia-se sobre o real sem a crítica do entendimento. Dito de outro modo, a ciência pretende capturar o real através de um raciocínio que transmuda o real.

Em suma, Bergson (1927/1988) põe em xeque um dos critérios empregados pela psicologia para legitimar-se como ciência: o afastamento radical do senso comum. Revela que conceitos nucleares da psicologia fundam-se na confusão entre qualidade e 
quantidade, bem como no engano de tratar o símbolo artificial da experiência como a experiência real. Ora, esses equívocos também estão presentes no senso comum. Nesse sentido, a ciência psicológica não opera uma ruptura completa do conhecimento ordinário, já que compartilha com este das mesmas ilusões fundamentais; portanto, não há um critério que diferencie qualitativamente o conhecimento produzido pela psicologia, enquanto ciência, do conhecimento supostamente superficial do senso comum. Como já foi mencionado, a marca distintiva entre a ciência e o senso comum parece ser meramente tecnológica.

\section{ANÁLISE DO CONCEITO DE GRANDEZA INTENSIVA: A TEORIA DA MULTIPLICIDADE}

A partir do diagnóstico sobre a confusão entre inextenso e extenso presente na ciência psicológica, o conceito híbrido de grandeza intensiva reclama um exame mais atento. Segundo Bergson (1927/1988), a depuração conceitual da noção de grandeza intensiva dá-se mediante a instauração de dualismos (qualidadequantidade, extenso-inextenso) que permite, ao final, apreender dois tipos de multiplicidade, irredutíveis um ao outro: a multiplicidade numérica e a multiplicidade qualitativa.

A primeira delas é representada pelo espaço: trata-se de uma multiplicidade de exterioridade recíproca, de simultaneidade, de justaposição, de diferença de grau. Aqui temos o divisível, mas que não muda de natureza ao dividir-se. As diferenças não são de natureza, mas diferenças de grau. Já a multiplicidade qualitativa se apresenta na duração pura: trata-se de uma multiplicidade interna, de sucessão, de heterogeneidade, de diferença de natureza. De acordo com Deleuze (1966/1999), embora Bergson muitas vezes tenha se referido à duração como indivisível, a duração também se "divide", porque é multiplicidade; mas "divide-se" mudando de natureza, sendo que em cada estágio de divisão temos o indivisível: "[na duração] há outro sem que haja vários; número somente em potência" (Deleuze, 1966/1999, pp. 31-32).

Diante da teoria da multiplicidade, podemos entender de uma outra perspectiva por que o conceito de grandeza intensiva é considerado por Bergson (1927/1988) um misto mal-elaborado. Ora, esse conceito tenta expressar a intensidade, que é pura qualidade, sob a "lógica" da multiplicidade numérica, em que temos a divisão sem mudança de natureza. Nesse caso, a mudança na sensação ou no sentimento é tratada, apenas, como mudança de grau. A intensidade acaba sendo encarada como uma propriedade matemática dos estados psicológicos; mas sensações e sentimentos, sendo inextensos, devem ser explicados em termos de multiplicidade qualitativa. Por exemplo, o sentimento de alegria, quando muda, muda de natureza. A intensidade desse sentimento não é expressa pelo aumento na amplitude de um único e mesmo sentimento, mas pelo envolvimento de "mais" estados psicológicos, irredutíveis uns aos outros, que vieram enriquecê-lo e modificar-lhe a natureza. Nesse sentido, podemos dizer que a confusão entre as duas multiplicidades define a falsa noção de intensidade que caracteriza o conceito de grandeza intensiva.

A decomposição de mistos, como o conceito de grandeza intensiva, não apenas nos mostra dois tipos de multiplicidade, mas também revela duas realidades primordiais, marca da filosofia bergsoniana: a extensão e a duração. É no interior desse dualismo que Bergson (1927/1988) dissolverá as confusões ou os "mistos" inerentes à psicologia ${ }^{2}$. Ora, Bergson argumenta que não só a experiência nos propicia mistos, já que é mediada pela linguagem, mas também que a própria medida do real consiste em um misto, como é o caso do conceito psicológico de grandeza intensiva.

Não obstante, a crítica de Bergson (1927/1988) à psicologia não se restringe aos seus conceitos basilares. A análise bergsoniana da categoria de grandeza intensiva e a discussão de duas

\footnotetext{
Há críticas quanto à afirmação de um dualismo fundamental em Bergson (1927/1988). Deleuze (1966/1999), por exemplo, ao discutir a intuição como "análise transcendental", ou seja, como aquela que nos leva às condições da experiência, argumenta que o dualismo é apenas um momento que culmina em um monismo. Com efeito, o real não se apresenta, unicamente, como diferenças de natureza, mas como o ponto ideal ou virtual onde estas diferenças convergem. Não obstante, no caso do Ensaio, a intuição não estava explicitada como método por excelência do bergsonismo, ainda que seu germe estivesse presente, por exemplo, na análise dos sentimentos profundos (Prado Jr., 1989) Além do mais, no Ensaio, Bergson localiza a duração na interioridade do sujeito, não oferecendo, ainda, condições para afirmar a dimensão temporal da exterioridade. Nesse caso, ele não radicaliza a sua proposta de dissolver as dicotomias presentes na tradição filosófica. Em suma, podemos dizer que há um dualismo no Ensaio que ora se destaca como uma espécie de metodologia para colocar problemas filosóficos em termos de diferença de natureza; ora como um dualismo fundamental e irredutível, presente na oposição essencial entre duração e extensão. Uma proposta de releitura do dualismo no Ensaio, circunscrendo-o no projeto fuldancional bergsioniano, consiste em uma análise atravessada pelo estudo do livro Matéria e memória (1896) que privilegia uma análise genética das condições da experiência como base de uma teoria do conhecimento psicológico (Deleuze, 1966/1999).
} 
multiplicidades distintas, a multiplicidade qualitativa e a multiplicidade numérica, têm como horizonte, no Ensaio, uma questão filosófica fundamental: a liberdade.

\section{A QUESTÃO DA LIBERDADE NA PERSPECTIVA BERGSONIANA}

De acordo com Bergson (1927/1988), o problema da liberdade nasceu de um mal-entendido, que tem sua origem na confusão entre sucessão e simultaneidade, duração e extensão, qualidade e quantidade. Esse malentendido está na raiz de metafísicas aparentemente contrárias, como o determinismo e o indeterminismo. Desse modo, deterministas e defensores do livrearbítrio compartilham de uma estrutura comum, o que acaba por uni-los, ao invés de consolidá-los como defensores de teses opostas.

Por que, não obstante, a liberdade parece ser um problema para Bergson (1927/1988)? A questão da liberdade é um problema por uma razão primeira: a experiência da liberdade é tratada em um plano discursivo. Nessa perspectiva, instala-se entre a consciência e ela mesma um abismo talhado pelo pensamento conceitual. Contudo, deterministas e indeterministas não fazem uma crítica do pensamento conceitual, e ludibriados pelas artimanhas da inteligência, acabam por considerar a representação simbólica da liberdade, ela mesma distorcida, como sendo a própria experiência da liberdade. Assim, na perspectiva bergsoniana, tanto os adversários quanto os defensores do livre-arbítrio fazem uma leitura indireta da liberdade, já que mediada pela estrutura da linguagem.

Por seu turno, a liberdade não sai ilesa dessa leitura: é transfigurada pela tendência espacializante inerente à linguagem, tornando-se uma experiência estática, e não dinâmica. O que Bergson (1927/1988) procura fazer é purificar a experiência da liberdade das máculas da linguagem, imergindo na experiência direta da liberdade, promovendo o encontro da consciência consigo mesma. Nesse processo de depuração conceitual, Bergson analisa um a um os argumentos do determinismo contra a liberdade, e os seus conceitos adjacentes, como o princípio da causalidade. A mesma operação é feita com respeito à tese indeterminista e ao seu acompanhante conceitual, a noção de contingência ou não-necessidade. Tal análise revela um procedimento tipicamente bergsoniano, em que se faz necessário o embate crítico com a forma tradicional de solução do problema, para, em seguida, apresentar uma teoria positiva da liberdade.

\section{DETERMINISMO E INDETERMINISMO}

Bergson (1927/1988) parte de uma situação de tomada de decisão para examinar os argumentos do determinismo e dos defensores do livre-arbítrio com respeito à liberdade. No caso do determinismo, o eu oscila entre duas alternativas, hesitando entre dois sentimentos contrários que permanecem inalteráveis durante todo o processo de decisão. Diante dessa situação de conflito, o determinista afirmará que a opção por uma das alternativas foi anteriormente fixada pelas condições antecedentes; e o sentimento de dúvida ou indecisão é somente decorrente de não termos consciência de todas as causas que determinaram a escolha de um dos caminhos propostos. Assim, a escolha não contém eventos contingentes: o que ocorrerá, ocorrerá necessariamente. Dito de outro modo, dizer que nossas ações são determinadas significa que diante de certas condições não podemos fazer o contrário - ou seja, não poderíamos nos comportar de modo diferente. Em que princípio o determinista fundamenta a afirmação de que a "escolha" já foi traçada pelas condições antecedentes?

O determinismo recorre à lei da causalidade, que, na perspectiva bergsoniana, envolve a suposição de que todos os eventos têm causas para sua ocorrência. Não só isso, o princípio de causalidade admite que causas semelhantes, sob circunstâncias semelhantes, produzem efeitos semelhantes. A repetição regular de uma sequiência causal parece ser o aspecto destacado por Bergson (1927/1988) para argumentar contra a possibilidade da aplicação do princípio de causalidade aos estados de consciência. Sobre esse ponto, consultemos as palavras do filósofo:

Dizer que as mesmas causas internas produzem os mesmos efeitos é supor que a mesma causa se pode apresentar repetidamente no teatro da consciência. Ora, a nossa concepção de duração tende apenas a afirmar a heterogeneidade radical dos fatos psicológicos profundos e a impossibilidade de dois dentre eles se parecerem completamente, já que constituem dois momentos diferentes de uma história. (...) não se pode falar aqui de condições idênticas, porque o mesmo momento não surge duas vezes (Bergson, 1927/1988, p. 38).

Isso sugere que a lei da causalidade não pode explicar o surgimento dos estados de consciência, não só porque eles não se repetem, mas também porque eles nem sequer se assemelham. Essa característica irreproduzível diz respeito não somente aos estados de 
consciência profundos (por exemplo: paixão, alegria, tristeza e sentimento estético), mas também àqueles estados em que é possível identificarmos uma causa exterior, como no caso dos estados de consciência pouco profundos (como as sensações). Mesmo que esses possam corresponder a uma causa exterior, não há razão para dizer, segundo Bergson (1927/1988), que a mesma causa produz o mesmo efeito, pois os estados de consciência têm vida própria, isto é, eles transformam-se continuamente. Assim, não há repetição de um estado, mas a produção de um novo a cada ocorrência. Diante disso, podemos dizer que o enunciado "mesmas causas e mesmos efeitos" parece não ser compatível com uma descrição dos estados de consciência, já que, neste último caso, lidamos com uma mudança qualitativa, e não quantitativa.

Ao questionar a aplicação do princípio de causalidade aos estados de consciência, Bergson (1927/1988) também critica o laço inexorável entre causa e efeito. Essa conexão infalível entre causa e efeito é entendida, na perspectiva bergsoniana, como uma pré-formação do evento futuro nas condições presentes. Afirmar que um evento causa outro evento é reconhecer que, dado o primeiro, já nos apercebemos do outro, ou ainda, que a idéia do segundo já está implicada na idéia do primeiro. Tratase, portanto, de enfatizar a determinação completa do efeito pela causa: diante da causa o efeito não poderia ter sido outro (lembremos da contrapartida desse raciocínio nas ações humanas: dado um conjunto de condições antecedentes, não poderíamos fazer $o$ contrário). Como veremos em momentos subseqüentes, a relação entre os estados de consciência não é expressa na teoria bergsoniana pela idéia de causalidade inexorável, mas sim, pela noção de virtualidade: o estado presente anuncia o estado futuro como possibilidade; e a realização do estado virtual é a realização do sentido do estado precedente, revelando um processo de mudança qualitativa a cada estado que se realiza.

$\mathrm{Na}$ esteira da discussão do princípio de causalidade, Bergson (1927/1988) argumenta que é indefensável a previsibilidade dos estados de consciência. Ora, o determinismo defende que o conhecimento de todos os antecedentes da ação futura nos permite formular uma previsão infalível - isso porque, como já mencionamos, o princípio de causalidade admite a possibilidade da repetição exata ou semelhante de uma seqüência causal de eventos. Nesse sentido, a contingência ou a probabilidade consistiria no mero produto da ignorância de todas as condições do ato. Para Bergson, a questão da previsibilidade dos fatos psicológicos mediante a captura dos antecedentes do ato é vazia de sentido. O argumento é o seguinte: para prevermos com precisão o comportamento de uma pessoa, teríamos de passar pela mesma série de estados psicológicos e chegar assim ao exato momento em que o ato se realiza. Para tanto, seria, pois, necessário ter passado por todas as fases do sentimento e ocupado a mesma duração. Ao passar pelos mesmos estados de consciência, tendo o mesmo passado e o mesmo presente, enfim, a mesma experiência, acabamos por nos tornar a pessoa cujo comportamento procurávamos prever; portanto, não se trata de prever o ato, mas de agir.

Em suma, Bergson (1927/1988) põe em xeque os princípios basilares do determinismo, como o princípio de causalidade e a sua contraparte epistemológica, a previsibilidade. Se a relação causal existe ainda no mundo dos fatos internos, não pode se assemelhar de nenhuma maneira ao que chamamos causalidade na natureza, já que um estado de consciência produz o seu efeito uma única vez, e nunca mais o produzirá.

Em oposição aos deterministas, os defensores do livre-arbítrio afirmam que somos livres para fazer nossas escolhas, pois no ato de optar por uma alternativa, a escolha de outra contrária também seria possível. Ou seja, os indeterministas questionam a noção de conexão necessária defendida pelos deterministas, afirmando que ser livre é poder fazer o contrário. Em outras palavras, se diante das mesmas circunstâncias nas quais agimos, supondo ainda as mesmas crenças e desejos, podemos fazer o contrário. Os indeterministas defendem que, ao agirmos livremente, alguma outra ação teria sido igualmente possível. Assim, ter consciência da liberdade é ter consciência de que podíamos optar pela alternativa contrária.

Para entender esta última afirmação, examinemos como Bergson (1927/1988) apresenta a concepção indeterminista de liberdade. Os indeterministas empregam uma espécie de notação para explicar o ato livre, qual seja: suponhamos que a série de nossos estados de consciência forme um caminho representado pelas letras $M O$, sendo $M$ o início deste caminho e $O$ o ponto a partir do qual este se bifurcará em duas alternativas distintas, $X$ e $Y$, que podem ser escolhidas após percorrido o caminho dos estados de consciência $(M O)$. As direções $X$ e $Y$ tornam-se coisas, indiferentes e invariáveis, que aguardam por nossa escolha. Em que ponto desse itinerário situa-se a atividade viva e contínua do $e u$ ? Estaria ela no ponto $O$ ? O indeterminista presume que sim: o $e u$, ao chegar neste ponto, delibera entre as duas alternativas, as bifurcações $X$ e $Y$, e escolhe uma delas. Temos, assim, 
segundo Bergson (1927/1988), um eu "indiferentemente ativo" (p. 124), que pondera entre os dois caminhos indiferentes e invariáveis. Se a opção for $X$, o caminho $Y$ ainda está disponível; se a escolha for por $Y$, a alternativa $X$ ainda permanece, aguardando nossa escolha. Bergson entende que esse é o sentido empregado pelos indeterministas quando afirmam que um ato livre envolve a possibilidade da escolha contrária.

O simbolismo geométrico adotado pelos indeterministas para definir a liberdade revela, na verdade, uma concepção mecanicista de liberdade (Bergson, 1927/1988). Em primeiro lugar, os indeterministas, quando tentam definir a liberdade representando-a simbolicamente, acabam por endossar o mais inflexível determinismo. Quando o indeterminista abstrai da atividade do $e u$ duas tendências opostas $(X \mathrm{e} Y)$, tal atividade, necessariamente, culminará ou em $X$ ou em $Y$; agora, quando o indeterminista localiza no ponto $O$ a dupla atividade do $e u$, não haveria motivo para separar essa atividade do ato ou escolha em que ela vai resultar. Se a escolha for por $X$, não é uma atividade inerte que se situa no ponto $O$, mas uma atividade já dirigida no sentido $O X$, a despeito das hesitações aparentes. $\mathrm{O}$ mesmo raciocínio se aplica à escolha por $Y$ : se a decisão for por $Y$, apesar de algumas tendências em escolher o contrário, é porque o ponto $O$ já estava predisposto a este caminho (Bergson).

Esclareçamos esse ponto: os indeterministas, tal como os deterministas, partem da ação realizada, isto é, de uma escolha concretizada, no caso, a escolha por $X$. O indeterminista, ao representar a escolha por $X$, começa justapondo os estados de consciência que se sucedem no interior do sujeito na forma de uma trajetória $M O X$. Partindo do simbolismo completo, os indeterministas retrocedem ao ponto $O$ e afirmam que toda a atividade do sujeito está situada nesse ponto, ignorando assim o caminho percorrido pelos estados de consciência $M O$. Isto supostamente os afastaria dos deterministas, que reconhecem que o caminho $M O$ foi percorrido, e que tal percurso constitui uma razão suficiente para a escolha por $X$. Mas ao localizarem a atividade do $\mathrm{eu}$ no ponto $O$ dizendo que uma outra ação $(Y)$ seria possível, os indeterministas também ignoram outra parte dos dados com a qual construiu o simbolismo geométrico: o trajeto $O X$; mas por que deter a atividade contínua do eu no meio do caminho? Por que não prolongá-la até o fim do percurso?

Ora, se o indeterminismo não ignorasse a atividade contínua do eu em todo o caminho MOX, ou seja, se não situasse, arbitrariamente, a atividade contínua do $e u$ apenas no ponto $O$, não haveria como separar a atividade do $e u$ do resultado final, a escolha por $X$. Desse modo, mesmo abrindo o caminho $Y$ a escolha por $X$ continuaria necessária. Em suma, os indeterministas partem de um fato necessário (o percurso $M O X$ ) para negar a sua necessidade. Todavia essa negação é feita de modo absurdo, pois reconhecem a atividade contínua do $e u$ durante todo o percurso, já que partem da figura completa, para depois desprezar a maioria do trajeto (admitem a atividade do sujeito apenas no ponto $O$ ). Por isso, o simbolismo empregado pelos indeterministas, tal como aquele empregado pelos seus adversários, também culmina na necessidade da ação. Nesse momento fica claro como os indeterministas caíram nas armadilhas da linguagem ou do pensamento conceitual: a representação simbólica da liberdade desemboca na sua tese oposta, o determinismo inexorável.

Em segundo lugar, podemos dizer que explicação indeterminista da liberdade é mecanicista, porque se dá mediante a refração do tempo no espaço:

Só pelo facto de pretendermos decompor o tempo concreto, desdobramos os momentos no espaço homogêneo; em vez do fato em vias de realização pomos o fato realizado e, como se começou por de alguma maneira congelar a actividade do eu, vê-se a espontaneidade dissolver-se em inércia e a liberdade em necessidade. - É por isso que toda a definição de liberdade dará razão ao determinismo (Bergson, 1927/1988, p. 151).

Daí o simbolismo expresso pela trajetória $M O$, que é um simbolismo de natureza mecanicista, que representa os sucessivos momentos como exteriores uns aos outros, de modo que se possa pensar em uma linha ou caminho $(M O)$ que atravessa o espaço. Ademais, Bergson (1927/1988) argumenta que não há dois estados contrários bem-definidos, ou melhor, duas coisas, mas uma multidão de estados de consciência sucessivos e diferentes que são separados por um esforço da imaginação em duas direções opostas. Não convém atribuir os sinais $X$ e $Y$, que são invariáveis, aos estados psicológicos, já que estes mudam continuamente. Ao fazer isso, estaríamos traindo a realidade concreta, pois, na verdade, não há direções distintas, "mas um eu que vive e se desenvolve pelo efeito das suas próprias hesitações, até que a acção livre se desprenda como fruto demasiado maduro" (Bergson, 1927/1988, p. 123). Por fim, o simbolismo empregado pelos indeterministas para explicar o ato livre trata com uma noção de tempo contaminada pelo espaço - mais 
especificamente, a noção de tempo homogêneo que será discutida adiante.

Como podemos apreender dessa discussão, o problema comum compartilhado pelo determinismo e indeterminismo, o qual acaba por questionar a aparente oposição entre essas teses, é pensar o ato livre retrospectivamente. Prado Jr. (1989) esclarece: "as aporias da liberdade nascem da confusão entre o ato livre, tal como ele é vivido presente e internamente, e a decisão objetivada no passado, como o momento de uma história já consumada" (p. 105). Tanto os deterministas quanto seus adversários pensam a decisão já consolidada, ou seja, sempre a "coisa já feita" em detrimento do seu "fazer-se", o que acaba tornando a experiência da liberdade estática, e não dinâmica.

\section{UMA FORMULAÇÃO NEGATIVA DE LIBERDADE}

Em vista dessas considerações, podemos apresentar uma concepção negativa de liberdade na perspectiva bergsoniana. Inicialmente, a liberdade não é ato imprevisível. Problematizar a liberdade no interior da dicotomia previsível versus imprevisível é admitir, em um primeiro momento, que os estados de consciência podem ser representados de um modo simbólico antecipadamente, o que é o mesmo que recuperar a equivalência entre tempo e o seu símbolo, tratando o tempo como um meio homogêneo. Cabe lembrar, ainda, que conceber todas as condições antecedentes do ato, na duração concreta, é realizar o próprio ato; é agir e não prever. $\mathrm{O}$ ato livre também não é aquele que não está determinado necessariamente por sua causa. Dar crédito a esta definição é reconhecer, a um só tempo, que os antecedentes psíquicos de um ato livre podem se reproduzir, que a liberdade se desenvolve numa duração cujos momentos se assemelham e que o tempo é um meio homogêneo, tal como o espaço. Ademais, o ato livre não é aquele que uma vez realizado poderia ter sido outro. Considerar a definição de ato livre como sinônimo de contingência acaba por legitimar, como foi discutido outrora, a necessidade absoluta culminando no mais implacável determinismo.

Notemos que os três sentidos de ato livre aqui discutidos carregam consigo o equívoco de tratar a duração como um meio vazio e homogêneo, discutindo o tempo com as propriedades do espaço. As definições tradicionais de liberdade são colocadas nos termos de uma ilusão que representa o tempo como espaço, tratando o ato livre em termos do tempo decorrido, e não do tempo que está a decorrer. Mas, “o acto livre", diz o filósofo, "produz-se no tempo que decorre, e não no tempo decorrido" (Bergson 1927/1988, p. 152).

O problema da liberdade funda-se na confusão de duas multiplicidades radicalmente distintas: multiplicidade qualitativa e multiplicidade numérica. A fusão das duas está no seio da noção de tempo homogêneo. Apesar de a multiplicidade qualitativa e a multiplicidade quantitativa apresentarem-se como realidades distintas, há uma comunicação entre elas, produto de um processo de endosmose. O tempo homogêneo é um conceito bastardo, produto desse processo, em que, de um lado, ocorre uma temporalização das regiões do espaço, que faz com que os pontos simultâneos pareçam suceder; e, de outro lado, uma espacialização dos estados de consciência, que faz com que os estados sucessivos possam ser medidos por esses pontos. Assim, a consciência introduz a sucessão nas coisas exteriores, e as próprias coisas exteriorizam os momentos da duração interna.

A liberdade é um problema, na medida em que seus termos são colocados sob a "lógica" do tempo homogêneo. É ele que permite fazer com que as coisas exteriores durem como nós e situar os nossos estados de consciência no espaço, sendo passíveis de mensuração. Com efeito, a noção de tempo homogêneo está na raiz de enunciados ditos "científicos", tais como: "os fenômenos internos estão submetidos às mesmas leis da natureza como os fenômenos objetivos"; ou ainda, "os fenômenos subjetivos e objetivos podem ser explicados pela mesma lei da causalidade". Em suma, o tempo homogêneo fundamenta a universalização do princípio de causalidade estendendo-o aos estados psicológicos (Bergson, 1927/1988).

É possível perceber que a distinção entre as duas formas de multiplicidade é que nos permite descobrir as raízes do problema da liberdade. Bergson (1927/1988) propõe que, ao estudar a liberdade, renunciemos ao compromisso entre multiplicidade qualitativa e quantitativa, e o façamos em proveito da duração, e não do espaço:

é preciso procurar a liberdade num certo cambiante ou qualidade da própria ação, e não numa relação do acto com aquilo que ele não é ou com o que poderia ter sido. Toda a obscuridade deriva de tanto uns como outros representarem a deliberação sob a forma de oscilação no espaço, quando consiste num progresso dinâmico em que o eu e os próprios motivos estão em um constante devir, como verdadeiros seres vivos (p. 127). 


\section{LIBERDADE E ESTÉTICA: CAMINHANDO PARA UMA CONCEPÇÃO BERGSONIANA DE LIBERDADE}

O que é esse progresso dinâmico? Onde podemos encontrar essa imagem que retrata um processo de constante devir que expressa a liberdade? Bergson (1927/1988) encontra as respostas no campo da estética, mais especificamente, na análise dos sentimentos profundos. Trataremos, aqui, em especial, do sentimento da graça. Podemos encontrar na descrição desse sentimento o exemplar de maior perfeição da experiência da liberdade. $\mathrm{Na}$ exposição do sentimento da graça, Bergson (1927/1988) inicia um processo de depuração conceitual, mostrando que o aprofundamento do sentimento estético não significa um acréscimo de uma quantidade, mas sim uma transformação de natureza. A descrição do sentimento do gracioso dá-se através da apresentação de figuras, que consistem nos momentos, irredutíveis uns aos outros, do processo de mudança qualitativa.

Inicialmente temos a figura da "facilidade do movimento", que busca retratar a ruptura das expectativas da percepção: "o movimento não parece estabelecer a relação normal de trabalho como seu ambiente" (Prado Jr., 1989, p. 81). O movimento, no contexto da sobrevivência e das relações sociais cotidianas, muitas vezes aparece na forma de esforço, de luta ou resistência às imposições da vida material e social. Em contraste, na experiência estética, ele ocorre sem oposição ou embaraço, o que lhe confere toda a leveza e delicadeza de um gesto figurando na dança. Prado Jr. elucida: "o sentimento da graça é, neste contexto, inicialmente, a interrupção da relação laboriosa com o mundo, suspensão imaginária do reino da necessidade e da inércia" (p. 82).

A transformação do sentimento da graça é representada em uma segunda figura, "a suspensão do tempo". Nesse momento, a facilidade do movimento é transmudada em "previsibilidade" do gesto futuro. O gesto presente anuncia em sua estrutura os contornos do gesto futuro. Esse prelúdio do gesto futuro no gesto presente é, ao mesmo tempo, a possibilidade de reter o futuro no presente ${ }^{3}$. A "previsibilidade" aparece como suspensão do tempo, assim, nessa situação, a

3 Podemos identificar, nessa passagem, um sentido de préformação distinto da conotação de determinação completa do estado posterior pelo anterior. Aqui a pré-formação sugere um outro tipo de relação entre os fenômenos, em que a figura seguinte é anunciada na anterior, mas não totalmente. Daí a possibilidade da criação em oposição à determinação inexorável, que trata da pré-formação do efeito na causa. experiência estética mostra-se como a experiência peculiar de uma temporalidade.

Finalmente, o sentimento da graça caminha para uma terceira figura, a "simpatia física", em que o ritmo se apresenta como o elemento central unificando sujeito e objeto, ou melhor, dissolvendo a dicotomia sujeito-objeto. A separação entre o eu e o outro desvanece, estabelecendo uma relação indissociável entre espetáculo e espectador, entre a visão e o visível: "o espectador não é apenas o beneficiário inessencial e intercambiável que recebe passivamente a "graça" do espetáculo da graça, é ele o dispensador último, é ele que suspende provisoriamente a legislação do mundo profano do trabalho da exterioridade" (Prado Jr., 1989, p. 84). A simpatia física traveste-se de simpatia moral ou "comoção", que revela a libertação última do movimento dos ditames da exterioridade. A descrição do sentimento da graça, mediante a apresentação das três figuras, pretende mostrar um processo de interiorização, que culmina na experiência da simpatia moral, no qual o "outro" torna-se "ele mesmo", ou ainda, "uma identificação interna do presente com aquele para quem há presença, iluminação interna do ser para ele mesmo" (Prado Jr., 1989, p. 103).

Podemos buscar uma formulação positiva da liberdade na própria descrição do sentimento da graça, que exibe o processo de interiorização em que se opera um retorno da consciência a si mesma. Em última análise, podemos dizer que encontramos no sentimento da graça o paradigma da experiência da liberdade: "a análise de todos os demais níveis da realidade psicológica reproduz o esquema esboçado pela descrição do sentimento da graça" (Prado Jr., 1989 , p. 87). A descrição do sentimento da graça permite captar o ato em vias de se fazer. Ora, é justamente esta a concepção de liberdade para Bergson (1927/1988), "o acto livre é a relação do eu concreto com o ato em vias de se fazer" (p. 152).

$\mathrm{Na}$ experiência da liberdade temos a experiência do tempo como continuidade, em que cada momento anuncia o momento futuro como possibilidade, ou melhor, virtualidade ${ }^{4}$. Em outras palavras, cada

\footnotetext{
Segundo Deleuze (1966/1999), a noção de virtualidade contrasta com a de atualização, sendo a primeira característica do subjetivo, da duração e da multiplicidade qualitativa; e a segunda do objetivo, do espaço e da multiplicidade numérica: "tudo é atual em uma multiplicidade numérica: nesta, nem tudo está "realizado", mas tudo nela é atual, comportando ela relações apenas entre atuais e tão-somente diferenças de grau. Ao contrário, uma multiplicidade não numérica, pela qual se define a duração ou a subjetividade, mergulha em outra dimensão, puramente temporal e não mais espacial: ela vai do virtual a
} 
momento contém a presença virtual, e não atual, da figura posterior. Com efeito, temos uma progressão, em que a última figura (simpatia moral, por exemplo) vem unir-se com aquelas que a anunciaram. Assim, ainda que cada momento seguinte seja considerado irredutível ao anterior, ou seja, a figura "facilidade do movimento" difere da figura "suspensão do tempo", cada uma sugere a forma da posterior "como se ela fosse o seu sentido". A realização da forma virtual é a realização do sentido da figura precedente. Temos, então, uma mudança qualitativa a cada figura que se realiza em um novo sentimento. Mas a diferença não é uma ruptura de sentido, pois os sentimentos caminham para uma significação primeira sem conhecê-la de antemão. Podemos dizer que cada parte contém (virtualmente) o todo, que é essa a significação primeira (Prado Jr., 1989) $)^{5}$.

Assim, a exposição do sentimento da graça parece tornar explícito um processo de totalização: a experiência da suspensão do tempo não significa um aumento de amplitude da experiência de facilidade do movimento, ao contrário, é um aprofundamento da anterior culminando em uma experiência que se radicaliza, cuja figura final expressa a essência do sentimento. A descrição do sentimento da graça revela não uma seriação de estados de consciência como instantes pontuais exteriores uns aos outros, mas um progresso qualitativo:

é, portanto, progresso na medida em que a significação inicial se enriquece, e é qualitativo na medida em que suas etapas são heterogêneas e acessíveis à consciência imediata sem qualquer recurso ao pensamento de estilo causal, que postula uma

sua atualização; criando linhas de diferenciação que correspondem a suas diferenças de natureza" (p. 32).

5 Na descrição do sentimento do belo podemos encontrar um exemplo esclarecedor do que significa a idéia de uma "divisão na duração" ou de uma multiplicidade qualitativa. Temos, aqui, portanto, uma multiplicidade, já que a descrição do sentimento do belo encerra "vários" sentimentos ou momentos (facilidade do movimento, suspensão do tempo e simpatia física). Mas trata-se de uma multiplicidade qualitativa, em que temos a divisão com mudança de natureza. Como acabamos de mencionar, a sucessão qualitativa dos estados de consciência revela figuras heterogêneas, cada uma apresentando características que lhes são próprias. Desse modo, no sentimento do belo há uma transformação envolvendo estados psicológicos distintos, o que contrasta com a noção de grandeza intensiva, discutida no início deste ensaio, que explica a mudança de intensidade não como uma mudança de natureza, mas apenas como mudança de grau de um único e mesmo sentimento. realidade em si como fonte e razão do processo (Prado Jr., 1989, p. 85).

A descrição do sentimento da graça, ao revelar a gênese qualitativa dos momentos que figuram no sentimento do belo, oferece-nos, a um só tempo, uma concepção dinâmica de liberdade, pois capta o ato no tempo que decorre e não no tempo decorrido, ou seja, o ato em vias de se fazer, e não o ato já feito. Em outras palavras, a descrição do sentimento do gracioso permite pensar a liberdade em termos de duração, colocando o problema da liberdade mais em função do tempo do que do espaço.

\section{PSICOLOGIA, ESTÉTICA E LIBERDADE: ALGUMAS CONSIDERAÇÕES}

Após examinarmos alguns aspectos que cercam o problema da liberdade na perspectiva de Henri Bergson (1927/1988), podemos indagar: que conseqüências a psicologia científica poderia extrair da análise do conceito bergsoniano de liberdade?

Inicialmente, a análise bergsoniana nos mostra que a liberdade é uma atividade - é um processo, e não de uma coisa. Em vista disso, podemos dizer que um dos primeiros desafios lançados por Bergson (1927/1988) à psicologia científica é o de lidar com um objeto de estudo dinâmico, e não estático. Mas como a psicologia científica poderia tratar de um objeto de estudo processual e fluido? Tal questionamento torna-se ainda mais espinhoso quando nos lembramos da crítica bergsoniana de que os instrumentos de medição e os próprios conceitos científicos acabam por coisificar a experiência de liberdade - isso significa, no vocabulário bergsoniano, espacializar o tempo, a duração. Ora, como burlar esse processo de substantivação operado pela linguagem?

Bergson (1927/1988) parece ter indicado um estratagema: a estética. Através da estética a psicologia teria condições de alcançar uma formulação precisa de liberdade. A noção de precisão bergsoniana não é meramente uma questão de método ou estilo, mas diz respeito à adequação ao objeto de estudo (Moore, 1996). Isso significa que, através da estética, a psicologia poderia ter êxito em conseguir uma formulação adequada a um objeto de estudo processual. Em suma, se ouvirmos as palavras de Bergson, a psicologia científica contemporânea deveria apresentar-se como psicologia estética.

Mas o que isso quer dizer? Primeiramente, a caracterização da psicologia como psicologia estética incita a psicologia a reconhecer a importância de resgatar o sensível como um modo de conhecer e se 
relacionar com o mundo. Insiste-se, pois, que a psicologia se debruce sobre o sensível - por isso, psicologia estética. Nessa linha, a psicologia deveria voltar-se para a investigação do saber sensível; um saber corporal, primordial e anterior aos processos de raciocínio e reflexão (Duarte Jr., 2001). Em segundo lugar, a reflexão bergsoniana acerca do papel da inteligência $e$ da linguagem na espacialização dos estados de consciência sugere que uma psicologia estética deveria não apenas estender o seu domínio ao saber sensível, mas antes disso, fazer uma crítica do saber intelectual examinando suas formas de expressão, como a linguagem. Há que questionar os consagrados pressupostos teóricos e metodológicos da psicologia científica, de forma que se construa uma nova maneira de se conhecer o mundo. Em tese "uma nova razão, em que se unam conceito e particularidade, abstração e concretitude, espírito e corpo, pensamento e sentimento" (Duarte Jr., 2001, p. 32).

Em última análise, podemos dizer que a discussão bergsoniana do problema da liberdade lança um desafio de caráter epistemológico à psicologia científica, qual seja: produzir conhecimento acerca do sensível, como objeto próprio do conhecimento sensível - conhecimento comumente preterido em favor do pensamento conceitual. Não se trata agora de desprezar o conhecimento intelectual, mas para que se possa cotejar devidamente o seu alcance, faz-se necessário aferir o escopo do saber sensível. Uma psicologia estética deveria criar condições para refletir as restrições do mundo da práxis, possibilitando o conhecimento de um mundo que surge a nós como objeto sensível, antes de ser tomado como matéria inteligível (Duarte Jr., 2001).

Dessa forma, a crítica de Bergson (1927/1988) a algumas propostas de psicologia científica à sua época acabou por gerar algumas expectativas com respeito à psicologia científica contemporânea: apresentar-se como uma psicologia estética, ou seja, uma psicologia que resgataria o saber sensível e assumiria uma posição crítica com respeito ao pensamento intelectual. Ora, essa provocação bergsoniana nos deixa com a seguinte questão: a psicologia estaria pronta para pensar a ciência como uma arte? Enfim, a psicologia científica estaria pronta para o belo?

\section{REFERÊNCIAS}

Bergson, H. (1988). Ensaio sobre os dados imediatos da consciência (J. S. Gama, Trad.). Lisboa: Edições 70. (Original publicado em 1927).

Deleuze, G. (1999). Bergsonismo (L. Orlandi, Trad.). São Paulo: 34. (Original publicado em 1966).

Duarte Jr., J. F. (2001). O sentido dos sentidos. Curitiba: Criar.

Moore, F. (1996). Bergson thinking backwards. Cambridge: University.

Prado Jr., B. (1989). Presença e campo transcendental. São Paulo: EDUSP.

Recebido em 18/08/06 Aceito em 16/11/06

Endereço para correspondência: Carolina Laurenti. Rua Rogério Mastrofrancisco, 71., bairro Castelo Branco, CEP 13571-130 São Carlos-SP. E-mail: carolinapsicologia@ hotmail.com 